\title{
The Role of Undercooling on Trace Element Partitioning in Sector- Zoned Clinopyroxene
}

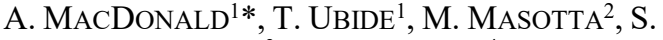
MOLLO $^{3}$, A. PONTESILLI $^{4}$

${ }^{1}$ The University of Queensland, Australia (*correspondance: alice.macdonald@uq.edu.au)

${ }^{2}$ University of Pisa, Italy

${ }^{3}$ Sapienza University of Rome, Italy

${ }^{4}$ Otago University, New Zealand

Clinopyroxene is an excellent recorder of magmatic processes, with a composition that reflects changes in magma chemistry and crystallisation conditions, including pressure and temperature ${ }^{[1]}$. In addition to concentric zonation, clinopyroxene crystals often exhibit sector zoning, where distinct domains (sectors) grow simultaneously with differing compositions. The hourglass sectors (along the c-axis) are depleted in Al-Ti compared to the prism sectors (which grown perpendicular to the c axis) ${ }^{[2][3][4]}$. Sector growth and partitioning has been related to the degree of magma undercooling (described by $\Delta T=$ liquidus temperature system temperature $)^{[5]}$. This presents an opportunity to explore processes such as magma recharge and ascent. Major element partitioning between hourglass and prism sectors has recently been investigated experimentally ${ }^{[6]}$, however trace element partitioning between sectors remains unconstrained.

Here we present preliminary trace element data on experimentally synthesised sector zoned clinopyroxenes crystallised at equilibrium and undercooled conditions. The starting compositon was based on a primitive trachybasalt from Mt Etna (Italy), in the Mount Maletto formation. Results from undercooling experiments indicate that trace elements including REE and HFSEs ( $\mathrm{Zr}, \mathrm{Ti}, \mathrm{Hf}$ ) preferentially partition into the prism sectors relative to the hourglass sectors.

We aim to quantify the relationship between sector trace element partitioning and undercooling in order to better understand trace element incorporation mechanisms and preeruptive procceses, which may occur under polybaric/polythermal conditions across volcanic plumbing systems.

[1] Ubide and Kamber, Nat. Commun. 9, 326 (2018). [2] Dowty, Am. Mineral. 61, 460-469 (1976) [3] Leung, Am. Mineral. 59, 127-138 (1974) [4] Ubide et al., Geochimica et Cosmochimica Acta, 251, 265-283 (2019) [5] Mollo and Hammer, EMU Notes in Mineralogy. 16, 373-418 (2017) [6] Masotta et al. Geochimica et Cosmochimica Acta. 268, 258276 (2019) 